\title{
Prevalence and Determinants of Unintended Pregnancies in Malawi
}

\author{
Palamuleni, Martin E. ${ }^{1}$ and *Adebowale, Ayo, $\mathbf{S}^{2,3}$ \\ ${ }^{1}$ Population Training and Research Unit, North-West University, Mafikeng, South Africa. \\ ${ }^{2}$ Post-Doctoral Research Fellow, Population Training and Research Unit, North-West University, \\ Mafikeng, South Africa \\ ${ }^{3}$ Department of Epidemiology and Medical Statistics, Faculty of Public Health, College of Medicine, \\ University of Ibadan, Ibadan, Nigeria \\ Email: Adehamilt2008@yahoo.com Phone: +23408033565210
}

\begin{abstract}
Available statistics indicate high levels of unintended pregnancies in Africa. This study examines the prevalence and determinants of unintended pregnancies in Malawi based on 2,144 pregnant women extracted from the 2010 Malawi Demographic and Health Survey. Data were analyzed using univariate, bivariate and multinomial logistic regression models. Nearly $43 \%$ of the pregnancies were unintended of which $25 \%$ were mistimed. Multivariate analysis indicated that mistimed pregnancies are significantly influenced by the age of the respondent, fertility preference and number of children ever born. Among the variables that significantly increased the likelihood of unwanted pregnancies are age of respondent, wealth status, fertility preference, and region of residence even though potential confounding factors were used as control. The study recommends the strengthening of family planning services in order to reduce the level of unintended pregnancies. Focus should be on couples in Central Region and those having large number of children.
\end{abstract}

Keywords: Unintended pregnancy; Demographic and Health Survey; prevalence; determinants; Malawi.

\section{Résumé}

Les statistiques disponibles abstraites indiquent les niveaux élevés des grossesses fortuites en Afrique. Cette étude examine la prédominance et les causes déterminantes des grossesses fortuites au Malawi basé sur 2. 144 femmes enceintes extraites à partir du Malawi 2010 démographique et de l'enquête de santé. Les données étaient les modèles logistiques univariables, bivariate et polynômes analysés de employer de régression. Presque $43 \%$ des grossesses étaient fortuits dont $25 \%$ ont été mal calculer. L'analyse multivariable $a$ indiqué que des grossesses mal calculer sont sensiblement influencées par l'âge du répondant, préférence de fertilité et nombre d'enfants jamais nés. Parmi les variables qui ont augmenté de manière significative la probabilité des grossesses non désirées sont l'âge du répondant, le statut de richesse, la préférence de fertilité, et la région de la résidence quoique des facteurs de confusion de potentiel aient été employés comme commande. L'étude recommande le renforcement des services de planification de famille afin de réduire le niveau des grossesses fortuites. Le foyer devrait être sur des couples dans la région centrale et ceux qui ont le grand nombre des enfants.

Mots clé: Grossesse imprévue ; Demographic and Health Survey ; prévalence ; déterminants ; Malawi

\footnotetext{
* Corresponding Author 


\section{Introduction}

Unintended pregnancy is an important public health concern in both the developing and the developed world because of its association with adverse social and health outcomes, for both mothers and children. The adverse outcomes include a high likelihood of unsafe abortion, late initiation and underutilization of prenatal care, and of low birth weight (Goto et. al. 2002; Nwokocha, 2006; Ikamari et. al 2013). The level of unintended pregnancy also can serve as an indicator of the state of women's reproductive health, and of the degree of autonomy women have in determining whether and when to bear children. It is important to identify factors associated with unintended pregnancy, to enable policymakers and program planners design legislation and services specifically for the women who are most likely to experience this problem.

An unintended pregnancy is a pregnancy that is either mistimed (pregnancies that occur earlier than desired) or unwanted (pregnancies that occur when no children, or no more children were desired) at the time of conception (Bongaarts, 1997). Unintended pregnancy is a potential hazard for every sexually active woman. It is a worldwide problem that affects women, their families, and the society. A complex set of social and psychological factors puts women at risk of unintended pregnancy. Abortion, infertility, child abandonment and maternal deaths are negative consequences of unintended pregnancies (Adetunji 1997; Bongaarts 1997; Nwokocha, 2006; Bradley et. al, 20I I; Kost, et. al. 2012; Ikamari et. al 20।3).

This paper examines the determinants of unintended pregnancy in Malawi where fertility has declined markedly between 1992 and 2011, contraceptive use has increased tremendously. For example, Total Fertility Rate (TFR) has marginally declined from 6.7 children per woman in 1992 to 6.4 children per woman in 2000 and 6.0 children per woman in 2004 (Malawi Government, 201 I). To a certain extent, this decrease in fertility reflects the increased availability and use of modern contraceptive methods. The contraceptive prevalence rate (CPR) has increased six-fold, from $7 \%$ in 1992 to $22 \%$ in 2004 and $46 \%$ in 2010 (Malawi Government, 1994, 201 I).

However, despite the decrease in overall fertility and associated increase in CPR, majority of women in Malawi-where induced abortion is illegal-still experience unintended pregnancies. Given Malawi's increased CPR it is reasonable to expect a decline in unwanted pregnancies in the country. However, available data indicate that the level of unwanted pregnancy has increased in recent years. For example, according to the 1992 MDHS, $20 \%$ of women in Malawi reported that their most recent pregnancy was unwanted. A similar percentage in 2010 was estimated at $28.2 \%$.

Studies on unintended pregnancies have received attention among demographers and public health practitioners in their efforts to understand fertility, prevent unintended childbearing, and to promote women's' ability to determine whether and when to have children (Bongaarts 1997; Bradley, Croft and Rutstein 201 I; Kost, et. al. 2012; Ikamari et. al 2013). Unintended pregnancy can result from contraceptive failure, non-use of contraceptives, and less commonly, rape. Further, it can create serious health consequences for women, children and family (Nwokocha, 2006; Kost, et. al. 2012; Ikamari et. al 20I3). There is very little published literature that focuses on the determinants of unintended pregnancy in developing countries and particularly in Malawi. However, some research studies conducted outside of Malawi have shown the relation between unintended pregnancy and socioeconomic and demographic characteristics (Kost, et. al. 2012; Ikamari et. al 2013). Moreover, there is very little known about unintended pregnancy in cultural contexts.

The incidences of unintended pregnancies are is common worldwide. Over 100 million acts of sexual intercourse take place each day resulting in around one million conceptions, about $50 \%$ of which are unplanned and about $25 \%$ are definitely unwanted (UNFPA, 1997). Data suggest that approximately $49 \%$ of all pregnancies in the United States (Finer and Zolna, 2006, 20II; Finer and Henshaw, 2006), $46 \%$ in Yamagata, Japan (Goto et. al. 2002), $43 \%$ in Kenya (lkamari et. al 20I3), $43 \%$ in Nigeria (Nwokocha, 2006), 35\% in both Iran (AbbasiShavazi et. Al. 2004; Najafian et. al. 20I0) and Nepal (Adhikari, et.al. 2009) are unintended. Almost all occurred due to nonuse of family planning method or contraceptive failure. About $50 \%$ of all unintended pregnancies in the United States are due to contraceptive failure (Finer and Zolna, 2006, 201I; Finer and Henshaw, 2006). Therefore, unintended pregnancy is an issue that cannot be ignored. Many pregnant women will want or need to end a pregnancy to avoid risks to their lives and 
health, psychological trauma, and socioeconomic turmoil.

The International Conference on Population and Development (ICPD) held in Cairo in 1994 and the fourth world conference on women held in Beijing in 1995 have emphasized women empowerment as a basic tool for a country's overall development and improving the quality of life of the people (United Nations, 1995). The ICPD declared that advancing gender, empowering women and eliminating all kinds of violence against women, and ensuring women's ability to control their own fertility are cornerstones of population and development related programs (United Nations, 1995).

Some studies indicate that nearly half of all unwanted pregnancies end up in abortion (Kinoti et al, 1995). Although abortion is illegal in Malawi, many women still seek abortion clandestinely and most often consult unskilled or unqualified health workers resulting in high rates of abortion related morbidity and mortality (Mtimavalye, 1996). Furthermore, a study conducted at five major hospitals in Malawi showed that abortion related hospitalization accounted for $20 \%$ to $48 \%$ of the total obstetric and gynaecological cases (Mtimavalye, 1996). Complications from spontaneous and induced abortions - primarily haemorrhage, infection and injury to the genital tract - remain a serious threat to the health of women in Malawi. These complications account for as much as $60 \%$ of acute gynaecological admissions into both public and private health facilities in Malawi (Kinoti et al, 1995). As well, an estimated $30 \%$ of maternal mortality in Malawi is due to complications of abortion (Levandowski, et. al. 201 I, Mtimavalye, 1996).

The underlying cause of high prevalence of unintended pregnancy needs further investigation and exploration in order to effectively implement appropriate reproductive health programs. It is essential to identify the risk factors of unintended pregnancy and to provide services to address those who are at risk. To develop effective strategies for the prevention of unintended pregnancies, it is necessary to understand the factors affecting unintended pregnancies. It is hypothesized that higher risks of unintended pregnancy is associated with socioeconomic and behavioural factors such as illiterate, living in rural areas, working in the agricultural sector, lack of exposure to mass media lead to low knowledge of family planning methods and low utilization of the health services.
Against this background, the objective of this study is to determine the prevalence and the factors influencing unintended pregnancy among currently pregnant women in Malawi. The findings of this study will be critical in guiding reproductive health program planners and policy makers to implement effective reproductive health programs that can reduce the risk of maternal and infant morbidity and mortality induced by unintended pregnancies. This study contributes to the existing literature by focusing on dynamics of unintended pregnancies among currently pregnant women.

\section{Data and Methods}

Data for this study come from the 2010 Malawi Demographic and Health Survey (MDHS), a nationally representative cross sectional household survey of women of reproductive ages (15-49 years). The primary purpose of the MDHS is to generate recent and reliable information on fertility, family planning, infant and child mortality, maternal and child health, and nutrition (Malawi Government 20II). The sample for the survey is based on a twostage, stratified, nationally representative sample of households. At the first stage of sampling, 257 Primary Sampling Units (42 in the urban areas; 215 in the rural areas) were selected using systematic sampling with probability proportional to size method. Out of 23,020 women of the reproductive age interviewed, 2,I44 (8.6\%) were currently pregnant at the time of the survey.

\section{Variables}

The dependent variable for this analysis, pregnancy status, was measured by respondents' perceived desire of current pregnancy. Women were asked the question: "At any time you became pregnant, did you want to become pregnant then, did you want to wait until later, or did you not want to have any (more) children at all? The three allowed options were wanted then (planned), wanted the pregnancy to happen later (mistimed) and did not want at all (unwanted). Since the dependent variable has more than two categories multinomial logistic regression was used. The multinomial regression model allows for multiple outcomes that are nominal in nature, rather than ranked in some meaningful ways. The multinomial regression model breaks the regression into a series of binary regressions, comparing each group to a baseline group. The reference group was women whose pregnancy was wanted. Multinomial regression will 
assess the odds of mistimed and unwanted pregnancies versus wanted pregnancies.

The independent variables were selected for inclusion in the analysis based on their significance in previous studies of pregnancy intention status or on their hypothesized association with pregnancy intention (Abbasi-Shavazi et al., 2004; Abdallah et. Al., 20II; Adhikari et. al., 2009; Eggleston, 1999). These variables were grouped into four: programmatic, demographic, socio-cultural and attitudinal. To make analysis and interpretation simpler and more meaningful, some variables were regrouped from their original categories in the dataset. All the independent variables, with exception of media exposure, were obtained from the various sections on the women questionnaire

In this study wealth index was constructed using the following household assets data: electricity, radio, TV, bicycle, motorbike and car. Each item was given a score of $\mathrm{I}$ if it available and 0 if it is not available and it was summed across items for each household. Individual wealth was ranked as poor; middle-class and rich, based on the total score. In other words, an individual was categorized as Poor if the total score was in the rage 0 to 2 ; middle, if the total score was 3 to 4 and rich if the total score was 5 to 6

Association between unintended pregnancy and the explanatory variables was assessed in bivariate analysis using Chi-square tests. Significant differences were determined using chi-square at $p<0.05$. Multinomial logistic regression was used to assess the net effect of several independent variables on unintended pregnancy. Before the multivariate analysis, multicollinearity between the variables was assessed and the least important variables were removed from the logistic model. Statistical Package for Social Science (SPSS) version 2I was used for analysis.

\section{Limitation of the Study}

There are some limitations to interpret the results of this study. First, the study population consisted of currently pregnant women at the time of the survey. This means that the obtained prevalence of women who reported unintended pregnancy should not be generalized to the general population in Malawi. The main objectives of this study are to determine the prevalence and examine the factors influencing unintended pregnancy among currently pregnant women Malawi. Thus, we intentionally selected a group of women who were currently pregnant during the period of survey, though risk factors of mistimed and unwanted pregnancy is not same, Second, because a cross sectional design of the study and all of the items analysed in the logistic regression analysis were information at the time of survey, the analysis can only provide evidence of statistical association between those items and the experience of unintended pregnancy and cannot show the cause-effect.

The concept of "intendedness of pregnancy" is complex and it would probably be better to treat it as a continuous rather than a bicategorical variable (Adhikari, et. al. 2009). Women are often unsure about their intention to become pregnant or not. Nonetheless, measures of unintended pregnancy that use the intended/unintended dichotomy remain valuable because they allow us to assess trends over time and differences among population subgroups (Adhikari, et. al. 2009). It has been shown that the perception of intendedness of pregnancy varies during the gestational period and after the delivery. As such some researchers have recommended the use of qualitative approach to capture such changes (Adhikari, et. al. 2009). The use of a measure of mistimed pregnancies may be especially problematic, since a birth can be mistimed by a short amount of time or a longer period of time, each possibly having different implications (Adhikari, et. al. 2009). Furthermore, many studies compare only intended pregnancies to unintended pregnancies, but do not examine mistimed and unwanted pregnancies separately, even though studies that do separate unwanted from mistimed pregnancies have found many differences in the mother's interpretation of pregnancy intention and the outcomes associated with it (Eggleston, 1999, 2000, Eggleston and Tsui, 200I). Moreover, if we take children born in the preceding five years or life time, that information may in fact underestimate unplanned childbearing since women may rationalize unplanned births and declare them as planned once they occur. The data used in this paper recorded the intendedness of current pregnancy among the currently pregnant women. It also minimizes underreporting of unintended pregnancy as well as reduces recall bias. In that sense, our study must be less biased than other studies that interview women at different times after 


\section{Results}

\section{Characteristics of Respondents}

Table I presents summary statistics of the study population. The percentage distribution of the study population increases from $17.1 \%$ in age group $15-19$ to $28.5 \%$ in age group $20-24$ after which it steadily declines reaching a minimum of $0.8 \%$ in age group 45-49. The majority of the study population were below the age 30 years $(71 \%)$ and the mean age was 26.7 years. The majority of the study population resided in the Southern Region (47.2\%), followed by Central Region and then Northern Region. The study population was predominantly rural with only $8.5 \%$ of the population residing in urban area. About $92 \%$ of the study population were married and most of these were in monogamous unions (88\%) with the spouse living with them (80\%). . About three out of four women had primary education (72\%) whereas women with no education and women with secondary and higher education comprised $14 \%$ each. Nearly half of the women reported that they are working $(50.7 \%)$ and only $13.2 \%$ of the study population could be categorised as rich.

Table I: Socio-economic characteristics of currently pregnant women in Malawi, 2010.

\begin{tabular}{|l|r|r|}
\hline Background Characteristics & $\mathbf{N}$ & $\%$ \\
\hline Age of respondent & & \\
\hline $15-19$ & 367 & 17.1 \\
\hline $20-24$ & 611 & 28.5 \\
\hline $25-29$ & 545 & 25.4 \\
\hline $30-34$ & 319 & 14.9 \\
\hline $35-39$ & 219 & 10.2 \\
\hline $40-44$ & 66 & 3.1 \\
\hline $45-49$ & 17 & 0.8 \\
\hline & 2144 & 100.0 \\
\hline Region & & \\
\hline Northern & 393 & 18.3 \\
\hline Central & 738 & 34.4 \\
\hline Southern & 2144 & 100.0 \\
\hline & & \\
\hline Type of residence & & \\
\hline 555 & & \\
\hline
\end{tabular}

\begin{tabular}{|c|c|c|}
\hline Urban & 183 & 8.5 \\
\hline \multirow[t]{2}{*}{ Rural } & 1961 & 91.5 \\
\hline & 2144 & 100.0 \\
\hline \multicolumn{3}{|l|}{ Marital Status } \\
\hline Never married & 68 & 3.2 \\
\hline Currently married & 1965 & 91.7 \\
\hline Formerly married & III & 5.2 \\
\hline \multicolumn{3}{|l|}{ Type of Marriage } \\
\hline Monogamy & 1638 & 84.1 \\
\hline \multirow[t]{2}{*}{ Polygamy } & 309 & 15.9 \\
\hline & 1947 & 100.0 \\
\hline \multicolumn{3}{|l|}{ Age at marriage } \\
\hline$<18$ & 1509 & 72.7 \\
\hline \multirow[t]{2}{*}{$>=18$} & 567 & 27.3 \\
\hline & 2076 & 100.0 \\
\hline Spouse Residence & 2144 & 100.0 \\
\hline Living with her & 1695 & 86.7 \\
\hline \multirow[t]{2}{*}{ Staying elsewhere } & 261 & 13.3 \\
\hline & 1956 & 100.0 \\
\hline \multicolumn{3}{|l|}{ Work Status } \\
\hline Not Working & 1057 & 49.3 \\
\hline \multirow[t]{2}{*}{ Working } & 1086 & 50.7 \\
\hline & 2143 & 100.0 \\
\hline \multicolumn{3}{|l|}{ Wealth Status } \\
\hline Poor & 958 & 44.7 \\
\hline Medium & 903 & 42.1 \\
\hline \multirow[t]{2}{*}{ Rich } & 283 & 13.2 \\
\hline & 2144 & 100.0 \\
\hline \multicolumn{3}{|l|}{ Education } \\
\hline None & 300 & 14.0 \\
\hline Primary & 1543 & 72.0 \\
\hline \multirow[t]{2}{*}{ Secondary+ } & 301 & 14.0 \\
\hline & 2144 & 100.0 \\
\hline \multicolumn{3}{|l|}{ Children Ever Born } \\
\hline 0 & 387 & 18.1 \\
\hline $1-2$ & 768 & 35.8 \\
\hline
\end{tabular}




\begin{tabular}{|c|c|c|}
\hline $3-4$ & 555 & 25.9 \\
\hline \multirow[t]{2}{*}{$5+$} & 434 & 20.2 \\
\hline & 2144 & 100.0 \\
\hline \multicolumn{3}{|c|}{ Children surviving } \\
\hline 0 & 455 & 21.2 \\
\hline $\mathrm{I}-2$ & 855 & 39.9 \\
\hline $3-4$ & 544 & 25.4 \\
\hline \multirow[t]{2}{*}{$5+$} & 290 & 13.5 \\
\hline & 2144 & 100.0 \\
\hline \multicolumn{3}{|c|}{ Fertility preference } \\
\hline wants more & 1085 & 51.3 \\
\hline Undecided & 84 & 4.0 \\
\hline \multirow[t]{2}{*}{ wants no more } & 946 & 44.7 \\
\hline & 2115 & 100.0 \\
\hline \multicolumn{3}{|c|}{ Desire to stop childbearing } \\
\hline No & 1085 & 53.4 \\
\hline \multirow[t]{2}{*}{ Yes } & 946 & 46.6 \\
\hline & 2031 & 100.0 \\
\hline \multicolumn{3}{|l|}{ Children dead } \\
\hline No Dead & 1465 & 68.3 \\
\hline I & 630 & 29.4 \\
\hline \multirow[t]{2}{*}{2} & 49 & 2.3 \\
\hline & 2144 & 100.0 \\
\hline \multicolumn{3}{|c|}{ Media Exposure } \\
\hline 0 & 454 & 21.3 \\
\hline I & 604 & 28.3 \\
\hline 2 & 779 & 36.5 \\
\hline \multirow[t]{2}{*}{3} & 299 & 14.0 \\
\hline & 2136 & 100.0 \\
\hline \multicolumn{3}{|c|}{ Heard about Family planning on radio } \\
\hline No & 819 & 38.2 \\
\hline \multirow[t]{2}{*}{ Yes } & 1325 & 61.8 \\
\hline & 2144 & 100.0 \\
\hline \multicolumn{3}{|c|}{ Heard FP on TV } \\
\hline No & 1986 & 92.7 \\
\hline Yes & 157 & 7.3 \\
\hline
\end{tabular}

\begin{tabular}{|l|r|r|}
\hline & 2143 & 100.0 \\
\hline Read about FP in Newspaper & & \\
\hline No & 1905 & 88.9 \\
\hline Yes & 237 & 11.1 \\
\hline & 2142 & 100.0 \\
\hline Visited by FP worker & & \\
\hline No & 1784 & 83.2 \\
\hline Yes & 359 & 16.8 \\
\hline & 2143 & 100.0 \\
\hline Visited health facility* & & \\
\hline No & 429 & 20.0 \\
\hline Yes & 1714 & 80.0 \\
\hline & 2143 & 100.0 \\
\hline
\end{tabular}

\section{Pregnancy Intention}

Table 2 shows that $46.7 \%$ of the study population indicated that their current pregnancy was wanted at that time. Of the remaining $53.3 \%$ who indicated that their current pregnancy was not wanted then, the pregnancy of $47.3 \%$ could be classified as mistimed and $52.7 \%$ was not wanted at all. The characteristics of women of each status were basically the same with a few exceptions. Women who indicated that the current pregnancy was wanted were younger than women whose current pregnancy was either mistimed of not wanted. The mean age for women of women who indicated that the current pregnancy was wanted was 25.5 years whereas those who indicated that the current pregnancy was mistimed or not wanted were 26.4 years and 29.2 respectively. Women who indicated that their current pregnancy was wanted had less number of children ever born than women whose current pregnancy was either mistimed of not wanted. The mean number of children ever born for women whose pregnancy was wanted, mistimed and not wanted was I.94, 2.6I and 3.29 respectively.

Table 2: Pregnancy Intention by selected background characteristic

\begin{tabular}{|l|l|l|l|}
\hline $\begin{array}{l}\text { Background } \\
\text { Characteristics }\end{array}$ & Wanted & Mistimed & $\begin{array}{l}\text { Not } \\
\text { wanted }\end{array}$ \\
\hline
\end{tabular}




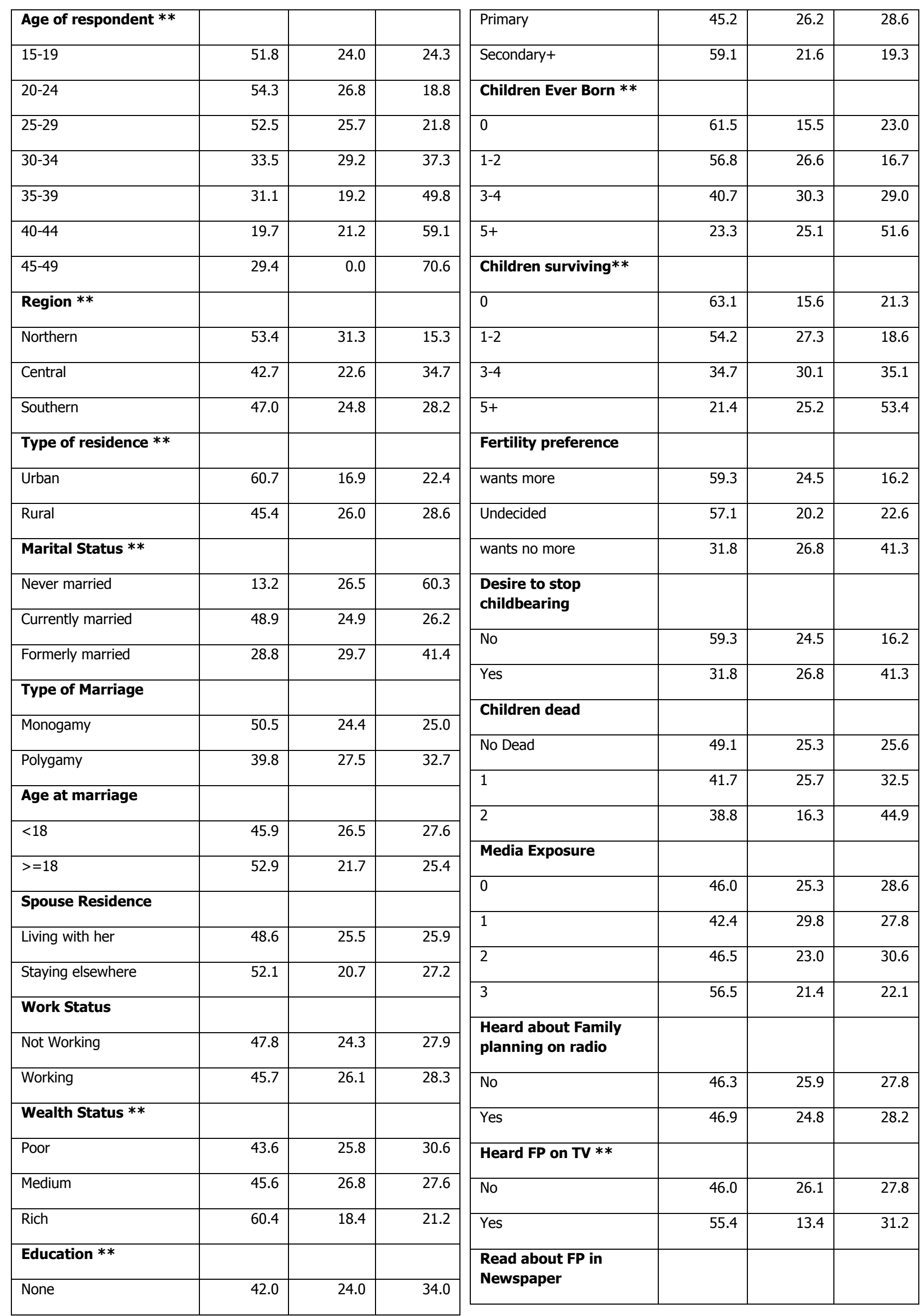




\begin{tabular}{|l|r|r|r|}
\hline No & 46.0 & 25.6 & 28.3 \\
\hline Yes & 52.3 & 21.9 & 25.7 \\
\hline Visited by FP worker & & & \\
\hline No & 46.1 & 25.6 & 28.3 \\
\hline Yes & 49.6 & 23.4 & 27.0 \\
\hline Visited health facility* & 50.1 & 20.5 & 29.4 \\
\hline No & 45.9 & 26.4 & 27.8 \\
\hline Yes & & & \\
\hline
\end{tabular}

\section{Bivariate Analyses}

Approximately $27 \%$ of respondents reported that their most recent pregnancy had been unwanted, $25 \%$ characterized the pregnancy as mistimed, and $48 \%$ classified it as planned (Table 2). Pregnancy intention varied significantly by all background characteristics considered. Further, the women most likely to have had an unwanted pregnancy differed from those most likely to have experienced a mistimed pregnancy. As expected, the percentage of women reporting unintended pregnancies increased with age $(24 \%$ of women aged less than 20 years to $70 \%$ of women aged 35 years and above). Similarly, women with higher birth order reported significantly higher rate of unintended pregnancy. Furthermore, women who got married at early age (before 18 years) had significantly higher rate of unintended pregnancy (46\%) compared with women who married while aged 18 years or older (36\%).

The results also show that rural women were more likely to have an unwanted pregnancy $(28.6 \%)$ than urban women $(22.4 \%)$. The same pattern is observed with mistimed pregnancy. Rural women were more likely to have a mistimed pregnancy (26\%) than urban women (16.9\%). Women living in the Central Region had the highest percentage of unwanted pregnancy (34.7\%), followed by women living in the Southern Region (28.2\%) and women in the Northern Region had the lowest percentage (I5.3\%). Mistimed pregnancies were highest in the Northern Region followed by the Southern Region and lowest in the Central Region.

With respect to socioeconomic status, results showed that women living in relatively poor households were most likely to report their pregnancy as unwanted $(30.6 \%)$, while those in the highest-income households were least likely to do so (21.2\%). However, women in middle-income

households were more likely than those of other socioeconomic backgrounds to classify their most recent pregnancy as mistimed. Unwanted pregnancies declined with the education level of the respondent. Women with no education had the highest percentage of unwanted pregnancies followed by women with primary education and lowest among women with secondary and higher education. Mistimed pregnancies were highest among women with primary education followed by women with no education and lowest among women with secondary and higher education. Women who were working had a higher percentage of unwanted pregnancy than women who were not working.

In the bivariate analysis, age and parity were both significantly associated with pregnancy intention. Older women (those aged 30-49) were more likely than younger women to say their pregnancy had been unwanted (33\% vs. 10-16\%), but women in their 20s were more likely than both younger and older women to have classified their pregnancy as mistimed (22\% vs. 12-17\%). High parity and unwanted pregnancy were clearly linked. Women with unwanted pregnancies had an average of 3.7 previous births while women with mistimed or planned pregnancies had 1.9 and 1.7 previous births, respectively (not shown).

The data further show that single women were more likely than women in union to report that their pregnancy had been unwanted ( $25 \%$ vs. $20 \%)$, while women in union were more likely than single women to have experienced a mistimed pregnancy (19\% vs. 12\%). Women with no formal education or who had not completed primary education were more likely to have had an unwanted pregnancy than women with some primary schooling. However, mistimed pregnancy was more common among women with primary schooling than among lesseducated women.

Unwanted pregnancy was also linked with knowledge of family planning. Both unwanted and mistimed pregnancies were more common among women who were knowledgeable and had ever used family planning than among those who were not knowledgeable and had never used family planning before their most recent pregnancy. Women who were visited by family planning workers in the 12 months prior to the survey had higher level of mistimed and unintended pregnancy compared to those who were not visited by family 
planning worker. Women who visited a health facility in the 12 months prior to the survey had lower unwanted pregnancies than women who did not visit a health centre. On the other hand women who visited a health centre had a higher percentage of mistimed pregnancies than women who did not visit the health centre.

\section{Multivariate Analyses}

All the variables that were statistically significant in the bivariate analyses were included in logistic regression in order to examine the correlates of unwanted pregnancy. The results of logistic regression analysis are presented in terms of odds ratio (if greater than unity, the probability of being a current user is higher than that of being a non-user), and $p$-values, to assess the relative importance of the selected variables.

Table 3: Multinomial logistic regression factors associated with pregnancy status in Malawi

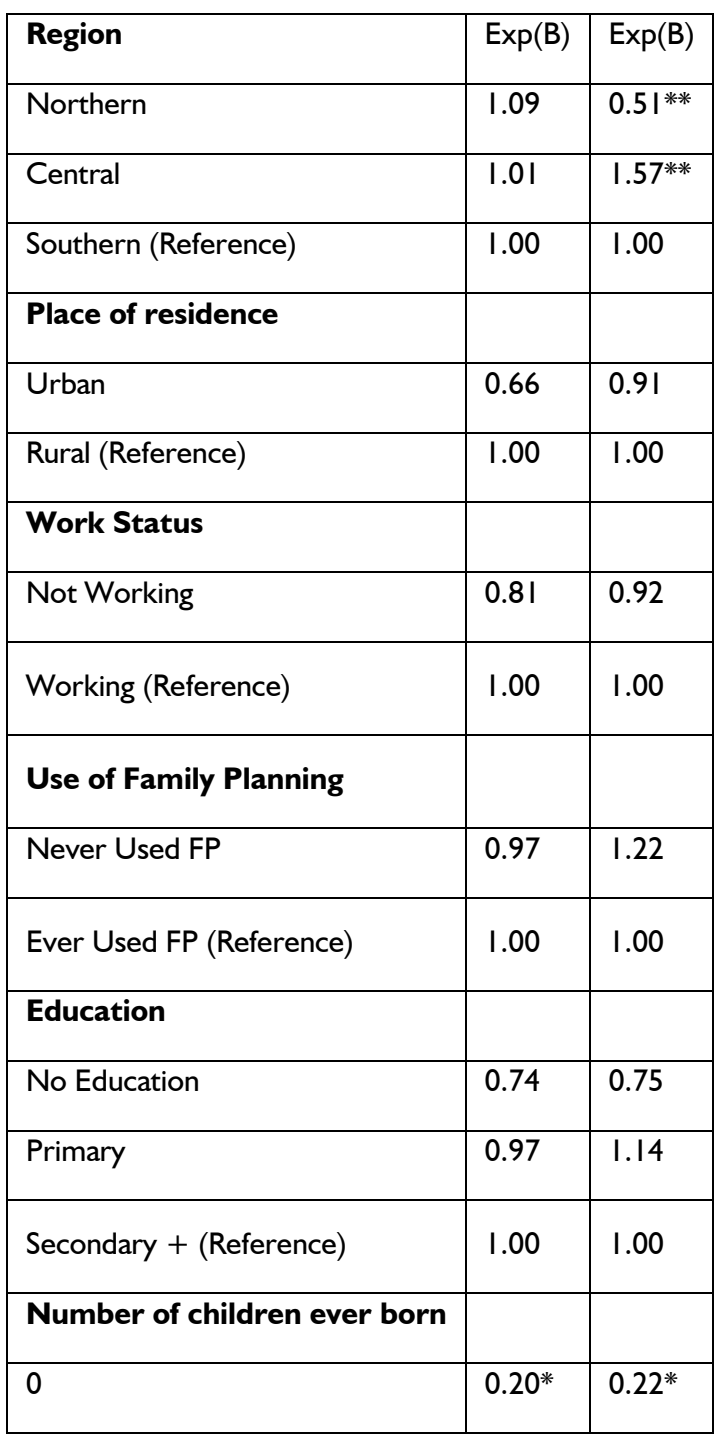

\begin{tabular}{|c|c|c|}
\hline $\mathrm{I}-2$ & 0.40 & 0.25 ** \\
\hline $3-4$ & 0.62 & $0.4 I^{*} * *$ \\
\hline $5+$ (Reference) & 1.00 & 1.00 \\
\hline \multicolumn{3}{|l|}{ Number of living children } \\
\hline 0 & $0.22 *$ & 0.33 \\
\hline $\mathrm{I}-2$ & 0.53 & 0.61 \\
\hline $3-4$ & 0.90 & 0.87 \\
\hline $5+$ (Reference) & 1.00 & 1.00 \\
\hline \multicolumn{3}{|l|}{ Fertility preference } \\
\hline Wants more & $0.6 I^{* *}$ & $0.29 * *$ \\
\hline Undecided & $0.42 * *$ & $0.33 * *$ \\
\hline Wants no more (Reference) & 1.00 & 1.00 \\
\hline \multicolumn{3}{|l|}{ Marriage type } \\
\hline Monogamy & 0.86 & 0.82 \\
\hline Polygamy (Reference) & 1.00 & 1.00 \\
\hline \multicolumn{3}{|l|}{ Children Dead } \\
\hline 0 & 2.05 & 2.08 \\
\hline I & 1.76 & 1.72 \\
\hline $2+$ (Reference) & 1.00 & 1.00 \\
\hline \multicolumn{3}{|l|}{ Heard FP on Radio } \\
\hline No & 1.07 & 0.92 \\
\hline Yes (Reference) & 1.00 & 1.00 \\
\hline \multicolumn{3}{|l|}{ Heard FP on TV } \\
\hline No & 1.69 & 0.73 \\
\hline Yes (Reference) & 1.00 & 1.00 \\
\hline \multicolumn{3}{|l|}{ Heard FP Newspaper } \\
\hline No & 0.89 & 0.92 \\
\hline Yes (Reference) & 1.00 & 1.00 \\
\hline \multicolumn{3}{|l|}{ Visited by FP worker } \\
\hline No & 1.35 & 1.26 \\
\hline Yes (Reference) & 1.00 & 1.00 \\
\hline \multicolumn{3}{|l|}{ Visited health facility } \\
\hline No & $0.68 *$ & 1.05 \\
\hline
\end{tabular}




\begin{tabular}{|l|l|l|}
\hline Yes (Reference) & 1.00 & 1.00 \\
\hline Age at first marriage & & \\
\hline$<18$ & 0.91 & 0.98 \\
\hline$>18$ (Reference) & 1.00 & 1.00 \\
\hline Wealth Status & & \\
\hline Poor & 1.21 & $1.68^{*}$ \\
\hline Medium & 1.30 & $1.65^{*}$ \\
\hline Rich (Reference) & 1.00 & 1.00 \\
\hline Age of respondent & & \\
\hline I5-19 & $6.40^{* *}$ & $2.57^{*}$ \\
\hline $20-24$ & $2.77^{*} *$ & 1.49 \\
\hline $25-29$ & 1.24 & 0.74 \\
\hline $30+$ (Reference) & 1.00 & 1.00 \\
\hline$*$ Signficant at $0.1 \% \% * S i g n$ & \\
\hline
\end{tabular}

*Significant at $0.1 \%$; * Significant at $5 \%$

\section{Correlates of mistimed pregnancy}

Results presented in Table 2 indicate that mistimed pregnancies are influenced by age of the respondent, fertility preference, number of children ever born, number of living children and whether or not women had visited a health facility in the last twelve months.

Women aged 15-19 years are 6.40 times more likely to indicate that the current pregnancy was mistimed than women aged 30 years and over. Women aged 20-24 years and 25-29 years are 2.77 and 1.24 times more likely to indicate that the current pregnancy in mistimed than women in the reference category. The odds ratio decreases with the increasing age of women suggesting that the incidence of mistiming decreases with age. Also, childless women were five times less likely to report that their current pregnancy was mistimed than women with 5 or more children. Women with no living children were 4.54 times more likely to report that their current pregnancy was mistimed than women with 5 or more living children.

Women who want additional children were 1.64 times less likely to report that their current pregnancy was mistimed than women who want more children. Women who are undecided were 2.38 times less likely to report that their current pregnancy was mistimed than women who want more children. Moreover, women who had not visited a health facility were 1.47 times less likely to report that their current pregnancy was mistimed than women who had visited a health facility 12 months prior to the survey.

\section{Correlates of unwanted pregnancy}

Multivariate logistic regression results in Table 3 show that the variables that influence whether or not a pregnancy is wanted were age of respondent, number of children ever born, wealth status, fertility preference, and region of residence. Younger women were more likely to indicate that the current pregnancy was not wanted than older women. Women in age group 15-19 years and 20-24 years were 2.57 and 1.49 times more likely to indicate that the current pregnancy was not wanted than women in the reference category. Women aged 2529 were 1.35 less likely to indicate that the current pregnancy was not wanted than women aged 30 years and over. The odds ratio decrease with increasing age suggesting that as women become older and mature the current pregnancy tend to be wanted.

Women in the Central Region were 1.57 times more likely to indicate that the current pregnancy was unwanted than women in the Southern Region whereas women in Northern Region are 1.96 times less likely to indicate that the current pregnancy was unwanted than the reference category. The results also showed that women who have no child were less likely to indicate that the current pregnancy was unwanted than women with five or more children. Women with I-2 children were less likely to indicate that the current pregnancy was unwanted than women with five or more children. The odds ratios increased with the increasing number of children suggesting that the more the number of children ever born the more likely for women to indicate that the current pregnancy was unwanted.

Fertility preferences also influence pregnancy status. Women who desire more children are less likely to indicate that the current pregnancy was unwanted than women who did not want additional children. Women who were undecided were less likely to indicate that the current pregnancy was unwanted than women who did not want additional children. Another variable affecting pregnancy status was wealth status of the women. Poor women were I.68 times more likely to indicate that the pregnancy was unwanted than rich women. Women in the medium category were 1.65 times more likely to 
indicate that the pregnancy was unwanted than rich women.

\section{Discussion}

This study investigated the factors influencing unwanted pregnancy in Malawi. The study showed that unwanted pregnancy is common among Malawian women thereby creating a high demand for family planning programs. Results from this study suggest that all women, regardless of age, socioeconomic, or socio-cultural status, would benefit from increased efforts to ensure that pregnancies are intended.

The bivariate analysis showed that the variables such as age, total children ever born, number of living children, age at first marriage, literacy status, radio exposure, travel time to the nearest family planning source, family planning workers' visit, religion, women's autonomy and knowledge about family planning methods are important in explaining unintended pregnancy. The multivariate analysis supported some of the findings of the bivariate analysis and indicated a different pattern of effect for few other variables. In the multivariate analysis, age of women, ideal number of children, age at first marriage, radio exposure, religion and knowledge about family planning methods were found to have significant influence on unwanted pregnancy.

This study has shown that the higher the age of women, the higher the probability of having current pregnancy as unintended. It is similar to the study conducted among currently married pregnant women in such countries such as Iran and Nigeria (Adetunji 1997; Abbasi-Shavazi, et. al. 2004; Najafian, et. al., 20I0; Geda and Lako, 20I2). In this study, we found significant relationship between age and unintended pregnancy in Malawi. Both mistimed pregnancies and unwanted pregnancies are higher among younger teenage women and decline with increasing age of the women. One of the reasons could be that young women are engaged in unprotected sex and are not married, which results in getting pregnancy outside marriage and is reported as unintended pregnancy. In Malawi teenage mothers are still ridiculed and discriminated. The non-use of contraception among teenagers could be due to limited access to services or may experience particular difficulty in practicing contraception.

The multivariate results showed that unwanted pregnancies vary by region of residence. Women residing in Northern Region were less likely to 561 report unintended pregnancy than those residing in the Southern Region whereas women in the Central Region were more likely to report unintended pregnancy than those who reside in the Southern Region. Regional differences in unwanted pregnancies have been observed in other studies (Kost, et. al., 20I2) and have been attributed to variations in the social and economic characteristics of the regions.

As expected, the present study found that women's wealth status has a significant impact on unintended pregnancy. This result is similar to finding of other studies (Nwokocha, 2006). It is often argued in the literature that in Malawi where most of the families are patriarchal, like other countries in sub-Saharan Africa, women are often given less opportunity to be self-supporting and control their own reproduction and depend on the male partners/relatives for their own social and economic survival. Women from poor households are more likely to have unwanted pregnancy than their rich counterparts.

Women who wants no more children or are undecided likely to report unintended pregnancy compared to those who desire more children. Our findings are consistent with findings from other studies in Africa that showed that fertility preference was a major factor for unwantedness of the present pregnancy (Adetunji 1997; Shaheen et. Al. 2007; Roudi and Monem 2009; Geda and Lako, 2012). In a society like that of Malawi where children are cherished and childbearing outside marriage is frowned upon, women who have no children or have few children or have children outside marriage are more likely to report unintended pregnancy than women who have more children or are married.

We hypothesized that women who have higher knowledge about family planning methods (more than average) are less likely to experience unintended pregnancy. Our results support the hypothesis that if a woman has higher knowledge of family planning methods, she is more likely to be aware of the benefits of those methods which in turn will motivate her to use the family planning methods and be less likely to have unintended pregnancy. The similar result is found in Ecuador as well (Eggleston, 1999, 2000; Eggleston et. al., 200I).

In this study, there was no significant association between the experience of unintended pregnancy and women's education. This is similar to the findings from studies conducted in Kenya, Japan and 
Nepal (Goto, et. al., 2002). However, this finding contradicts conventional wisdom and other studies on the correlates of unintended pregnancy (Finer and Henshaw, 2006; Finer and Zolna, 20II). In Malawi, very few women are educated and the majority of women prefer to have more children. As such there is no significant difference in the experience of unintended pregnancy among different educational levels. However, it should not be concluded that education is not significantly related to intended pregnancy status and thus we should not ignore the importance of education for the better life of women.

Ever use of family planning method has significant relationship with intended pregnancy status of women in many literatures. However, the result from this study is not similar to those findings. Some of the reasons identified were the complexity of using contraceptive or lack of methods choice and financial barriers hindering effective use of contraceptive methods. It was seen that the individual or community perception about contraception is an important factor, which affects contraceptive use. Similarly, misconception leads to discontinuation and decreased use of contraception and increases the level of unintended pregnancy (Adhikari, et. al. 2009). Thus, it can be argued that misconception about family planning methods exist among Malawi women. High family planning method failure among married women in the reproductive age has also been cited as a reason for unintended pregnancies in other countries (Adhikari, et. al. 2009). However, it does not imply that contraceptive use is not an important determinant of unintended pregnancy among married pregnant women in Malawi, it rather reflects the situation that the variable ever use of family planning methods acts indirectly on unwanted pregnancy in this study.

\section{Conclusion}

In conclusion, no single factor accounted for the high rates of unintended pregnancy. Many factors contributed in this regard. Among them, this study has found that age of women, children ever born, region, fertility preferences and wealth statues are firm predictors of unintended pregnancy. In short, it can be concluded that the reproductive health program should aim to reduce unintended pregnancy by focusing on all these identified factors so that infant and maternal mortality and morbidity as well as the need for abortion is decreased and the overall well-being of the family is maintained and enhanced.

\section{Acknowledgements}

The authors thank the ICF Macro Calverton, Maryland, USA for releasing the data for this study. We also appreciate the efforts of the National Statistical Office of Malawi and the Malawi Government for coordinating and conducting the survey.

\section{Reference}

Abbasi-Shavazi MJ, Hosseini-chavoshi M, Aghajanian A, Delavar B, Mehyar A. 2004. "Unintended pregnancies in the Islamic Republic of Iran: Level and Correlates". Asia-Pacific Population Journal, 19(I):27-38.

Abdallah IM, Mone'm EFA, Abd El Sabour Hassan M. 2011. "Determinants and Outcomes of Unintended Pregnancy among Women in Helwan District" Journal of American Science, 7(I I):497505.

Adetunji J. 1997. "Levels, trends, and determinants of unintended childbearing in developing countries", paper presented at the annual meeting of the Population Association of America, Washington, DC, March 27-29, 1997.

Adhikari R, Soonthorndhada $K$ and Prasartkul P. 2009. "Correlates of unintended pregnancy among currently pregnant married women in Nepal" BMC International Health and Human Rights, 9:17 doi: I0.I I86/I472-698X-9- I7.

Bradley, S.E.K., Croft TN, and Rutstein SO. 201 I. The Impact of Contraceptive Failure on Unintended Births and Induced Abortions: Estimates and Strategies for Reduction. DHS Analytical Studies No. 22. Calverton, Maryland, USA: ICF Macro.

Brown SS and Eisenberg L. 1995. The Best Intentions: Unintended Pregnancy and the WellBeing of Children and Families. Washington, DC: National Academy Press.

Bongaarts J. 1997. "Trends in unwanted childbearing in the developing world", Studies in Family Planning, 28(4):267-277.

Cheng D., Schwarz E B., Douglas E., Horon I. 2009. "Unintended pregnancy and associated maternal preconception, prenatal and postpartum behaviours". Contraception, 79(3): 194-198.

D'Angelo, D. V., Gilbert, B. C., Rochat, R. W., Santelli, J. S. and Herold, J. M. 2002. "Differences between mistimed and unwanted pregnancies among women who have live births". 
Perspectives on Sexual and Reproductive Health. 36(5): 192-197.

Eggleston E. 1999. "Determinants of Unintended Pregnancy among Women in Ecuador" International Family Planning Perspectives 25(I):27-33.

Eggleston E. 2000. "Unintended pregnancy and women's use of prenatal care in Ecuador". Social Science and Medicine 5I: $10 \mathrm{II}-1018$.

Eggleston E., Tsui A.O. and Kotelchuck M. $200 \mathrm{I}$. "Unintended Pregnancy and Low Birth weight in Ecuador". American Journal of Public Health, 9I(5):808-810

Finer LB and Henshaw SK. 2006. "Disparities in rates of unintended pregnancy in the United States, 1994 and 200I". Perspectives on Sexual and Reproductive Health, 38(2):90-96.

Finer LB and Zolna MR. 20II. "Unintended pregnancy in the United States: incidence and disparities, 2006". Contraception, 84(5):478485.

Geda, N.R. and Lako, T.K. 20I2. "Unintended pregnancy among married women in Damot Gale District, Southern Ethiopia: Examining the prevalence and risk factors" African Population Studies 26(I):96-I I 2.

Goto A., Seiji Y., Michael R.R. and Akira F. 2002. "Factors associated with unintended pregnancy in Yamagala, Japan”. Social Science\& Medicine.; 54 (7): 1065- 79.

Hellerstedt, W. 2004. "Pregnancy Intention: Why Do We Measure It and Can We Measure It?" Healthy Generations, Volume 5 Issue I, Maternal and Child Health Program, School of Public Health, University of Minnesota.

Ikamari, L., Izugbara, C and Ochako, R. 2013. "Prevalence and determinants of unintended pregnancy among women in Nairobi, Kenya" BMC Pregnancy and Childbirth, 13:69

Kost, K. et. al. 2012. "Variation in State Unintended Pregnancy Rates in the United States" Perspectives on Sexual and Reproductive Health 44(I):57-64.

Levandowski , B.A. et. al. 20II. "The estimated incidence of abortion in Malawi", paper presented at Population Association of America
(PAA) Annual Meeting, Washington DC, USA, 30 March - I April, 200 I.

Malawi Government . 1994. Malawi Demographic and Health Survey 1992, National Statistical Office and Macro International Inc., Zomba.

Malawi Government. 1997. Malawi Knowledge, Attitudes and Practices in Health Survey 1996, National Statistical Office and Macro International Inc., Zomba.

Malawi Government. 2002. Malawi Demographic and Health Survey 2000, National Statistical Office and Macro International Inc., Zomba.

Malawi Government. 2006. Malawi Demographic and Health Survey 2004, National Statistical Office and Macro International Inc., Zomba.

Malawi Government. 20II. Malawi Demographic and Health Survey 2010, National Statistical Office and Macro International Inc., Zomba.

Mohllajee, A. P., Curtis K. M., Morrow B., Marchbanks P. A. 2007. "Pregnancy Intention and its Relationship to Birth and Maternal Outcomes" Obstetrics and Gynecology; 109:678-86.

Najafian M., Karami K. B., Cheraghi M., and Jafari. R M. 2010. "Prevalence of and Some Factors Relating with Unwanted Pregnancy, in Ahwaz City, Iran “ ISRN Obstetrics and Gynecology, vol. 20II, Article ID 523430; I - 4.

Nwokocha, E.E. 2006. "Pregnancy Outcomes Among The Ibani Of Rivers State, Nigeria: Findings From Case-Studies" African Population Studies 2I(I):93-II8.

Pulley, L. V., Klerman, L. V., Tang, H. and Baker, B. A. 2002. "The extent of pregnancy mistiming and its association with maternal characteristics and pregnancy outcomes". Perspectives on Sexual and Reproductive Health; 34(4): 206-2I I.

Roudi F and Monem AA. 2009. "Unintended Pregnancies in the Middle East and North Africa" paper presented at the IUSSP International Population Conference, Marrakech 2009.

Shaheen AA., Diaaeldin M., Chaaya M. and EIRoueiheb Z. 2007. "Unintended pregnancy in Egypt: evidence from the national study on women giving birth in 1999". Eastern Mediterranean Health Journal; 13(6), 1392 . 1404. 